\title{
Implementing new flood protection standards: obstacles to adaptive management and how to overcome these
}

\author{
Frans Klijn ${ }^{1,2, a}$, Nathalie E.M. Asselman ${ }^{1}$, Arno de Kruif ${ }^{3}$, Pieter J.T.M. Bloemen ${ }^{4}$ and Marjolijn Haasnoot ${ }^{1,2}$ \\ ${ }^{1}$ Deltares, PO Box 177, 2600 MH Delft, Netherlands \\ ${ }^{2}$ Delft University of Technology, Department TPM, Jaffalaan 5, 2628 BX Delft, Netherlands \\ ${ }^{3}$ Editorial Rijkswaterstaat WVL, PO Box 17, 8200 AA Lelystad, Netherlands \\ ${ }^{4}$ Staff Delta Commissioner, PO Box 90653, 2509 LR The Hague, Netherlands
}

\begin{abstract}
The Netherlands is updating its flood protection, whilst fully taking into account climate change and socioeconomic development. This translates in 'anticipatory standards' which need to be met in 2050, and which apply for the then foreseen climate and economy. Whilst the government maintains to have adopted a policy of adaptive planning and management, the new standards are thus based on one future situation, which qualifies as a 'high end scenario' from a flood risk management perspective. The consequences of adopting these new standards are now becoming clear. It is expected that many hundreds of kilometres of primary flood defences need to be reinforced and/or raised, at an estimated investment of about 9-14 billion euros. The many uncertainties about actual future development, however, complicate the decision making about the implementation of individual reinforcement projects: should one aim at immediately meeting the new standard or gradually improve and grow towards it? In this paper we discuss the uncertain decision making context, show that lawfulness (working according to procedures, rules and regulations) and expediency (towards a purpose) may jeopardize the good intentions of adaptive management, and argue that optimization may not provide the most useful answer to this decision making problem.
\end{abstract}

\section{The Netherlands' Delta Programme and adaptive delta management as policy paradigm}

The Netherlands largely consists of fluvial and coastal plains and can be viewed as a huge delta built-up by the rivers Rhine, Meuse and Scheldt. These fluvial and coastal plains, and even large freshwater bodies and shallow parts of the former Zuiderzee (Southern Sea), have been reclaimed and turned into prosperous agricultural polders in which major cities have developed. Consequently, over $55 \%$ of the country is flood-prone, whereas $26 \%$ presently lies below mean sea level. Obviously, the Netherlands thanks its sheer existence to its flood defence infrastructure, its drainage and irrigation network and its delta technology at large. This infrastructure has been built over many centuries, but it requires constant maintenance, improvement and adaptation to changing conditions.

The now expected further climate change, sea level rise and subsidence urge the country to negotiate the steadily increasing flood hazard. At the same time the expected further population growth and economic

\footnotetext{
${ }^{\mathrm{a}}$ Corresponding author: frans.klijn@deltares.nl
}

development call for sound spatial planning, as they tend to make the country increasingly more vulnerable to flooding [ $1-5]$. Actually, it had already been established that the legal flood protection level in many parts of the country was not adequately tuned to the past increase in population and economy since these levels were derived in the 1960s; the current protection standards were found to be both outdated and insufficiently risk-based [6].

Against this background, the Netherlands' government solicited advice from an independent committee, which recommended on a national Delta Programme, with a Delta Fund and a Delta Commissioner to ensure its implementation [7]. The committee suggested raising the flood protection level by a factor of 10 overall, as well as raising the water level in the IJsselmeer (Lake IJssel) in order to provide for a large spare freshwater resource. In 2010 the Delta Programme has been formally established and has first been tasked to draft a long-term adaptation strategy for integrated water management and spatial planning in view of the changing climate and the rising sea level [8]. The leading thought of the Delta Programme is that the country should anticipate climate change and socio-economic 
developments and their likely consequences in terms of increased flood and drought risk, instead of respond to flood or drought disasters after they happened. And not by brute force from the beginning onward, which could turn out to be an overinvestment, but by gradual adaptation and keeping options open for more drastic interventions in the future, when physical conditions were to justify these. This has been coined as 'adaptive delta management' [8].

Adaptive delta management differs from the many centuries of adaptation in the past and from what is usually described in literature as the essence of adaptive management [e.g. 9 - 12] in that it calls for anticipation instead of response, and because it explicitly recognizes and takes account of uncertainties about the future. Where conventional adaptive management often relies on trial-and-error, adaptive delta management seeks to plan in anticipation, based on policy analyses [13, 14] applying scenario analysis [4,5] and exploratory modelling [15].

Free after Van Rhee [16] we recognise four principles for adaptive delta management in practice, namely:

- short term decisions should contribute to longterm objectives in flood risk and water resources management, primarily those related to sustainable development;

- adaptation pathways should be identified with successive policy actions over time, rather than that a final situation should be defined for some point in the future ('blue-print planning'); this allows for exploring path-dependencies, lock-in and lock-out situations, and the flexibility of actions in general;

- flexibility should therefore be sought and valued, both in individual measures and in comprehensive strategies, in order to allow for speeding up or slowing down and in order to prevent regret of underperformance or overinvestment; and related to this:

- synergies should be aimed for, with goals and development initiatives by other public and private parties, thus also reducing the likelihood of regret because other benefits have been achieved.

Although these principles may sound very obvious, especially the first one, their practical application is not without complications, as we shall illustrate in this paper by an actual practical case. This case comes from the Delta Programme, more specifically the programme on flood risk management, which first and foremost performed an analysis in order to define the most efficient and societally desirable flood protection standards [17]. After ample negotiations with all relevant stakeholders, the final proposal for these new standards is bound to become legal by 2017. Meanwhile, many embankments are being reinforced and redesigned in view of these new standards. A challenge is to do so while at the same time applying the principles of adaptive delta management.

\section{A first concrete policy decision: new flood protection standards}

The Delta Programme was tasked to revise the Netherlands' flood risk management policy. This revision encompassed an actualisation in order to account for the grown population and economy, a modernisation in order to better align with the best-practices of comprehensive flood risk management as prescribed by the EU-Floods Directive and further established in various EU-projects and by international comparisons [18, 19], and anticipating future changes. Key elements of the revision are multiple-tiered flood risk management, which means not only relying on 1) flood protection but also 2) accounting for flood risk in spatial planning and 3) emergency management planning. Most effort went into updating the protection standards, however.

This update involved a risk-based approach, a better foundation on improved data and modelling techniques, as well as fully taking into account climate change and socio-economic development. Where the Delta Programme as a whole relied on the analysis of what might happen in the future in four different so-called 'delta scenarios', the revision of the protection standards relied on the analysis of one scenario for climate change and socio-economic developments only [cf. 20], supplemented by a sensitivity analysis. This resulted into what may be called 'anticipatory standards', derived for a relatively pessimistic estimate of climate, sea level, population and economy in about 2050.

The new standards are founded on a number of basic criteria [17], namely economic efficiency, social equity and sustainability. The criterion on economic efficiency was accounted for by performing a benefit-cost analysis [20], in order to define which degree of protection would yield sufficient return on investment in terms of reduced risk levels and thus - in the end - less flood losses. This economic rationality may, however, result in very good protection of densely populated and economically vital areas, whereas other areas may be worse off because improving the protection level would be too costly in comparison to the number of people and economic stock at stake. Therefore, the minister decided to provide a basic level of protection to everybody living in protected area. With this criterion on social equity the protection standard was raised in order to achieve a fatality risk not exceeding 10-5/yr. Or in other words: the individual probability to die due to flooding should be less than 1 : 100.000 per year $[17,21]$. Thirdly, in cases where a flood might cause societal disruption because of vital infrastructure being hit, cascade-effects, large numbers of fatalities, or long-term disruption of public life or business, the protection standard was raised further. This accounts for the sustainability criterion with respect to the country's socio-economic functioning.

The underpinning of the thus founded protection standards relied on 1) cost-benefit analysis [20], 2) estimates of Flood Fatality Hazard [21], and 3) loss-oflife modelling per breach location and related expert judgement on cascade effects and consequences for vital infrastructure of each breach. In the cost-benefit analysis 
loss of life and psychological impacts were taken into account by setting a price on each fatality and otherwise affected person [20]. The economic damage and number of killed and otherwise affected persons were established for a large number of breaches, based on flood simulations which were considered representative for embankment stretches. On the other side, the cost-benefit analysis took into account both the investment costs and maintenance costs of flood protection, assuming embankments to be the main measure implemented.

Flood fatality hazard was established on the basis of the same flood simulations for breaches in all embankment stretches. By assuming a certain effectiveness of evacuation and the application of a lossof-life model with mortality curves for water depth and water level rising speed, we could calculate the probability of drowning of a hypothetical person on every spot in the country [21]. By backward modelling the acceptable probability of breaching could then be established for each embankment stretch.

The loss-of-life estimates were also used to quantify the number of casualties per breach as a proxy for societal disruption, whereas cascade effects and consequences for vital infrastructure were assessed on the basis of expert judgement.

All in all, the proposal for the new protection standards was defined by taking the strictest of the outcomes. In practice, for about a third of the stretches the standard was determined by the outcome of the costbenefit analysis only, slightly fewer than one third by the criterion on basic individual protection, whereas for the remainder the two criteria led to a similar outcome. Only for some stretches the proposal has been made stricter because of considerations about potential societal disruption. The proposal for the thus derived flood protection standards was turned into a concept for change of the Water Act. It is expected that the Act will pass parliament in 2016 and become in force by 2017.

In hindsight, we may conclude that the new standards are thus based on a possible future socio-economic and climatic situation, which could be qualified as a 'high end scenario' from a flood risk management perspective. This is rational in the context of exploring how big the problem to face might be, but it is quite a challenge to match this with the government's claim to have adopted a policy of adaptive planning and management. We shall explore some possible consequences for reinforcement planning and make some suggestions on how one might proceed in practice.

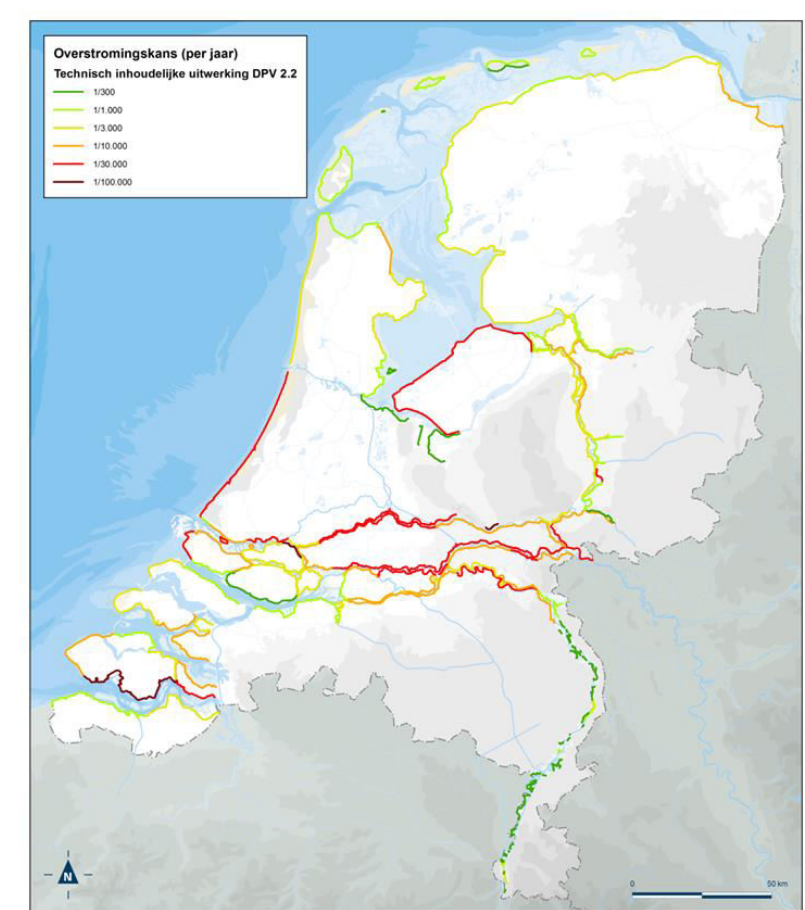

Figure 1. Proposed new flood protection standards in terms of maximum acceptable failure probability of embankment stretch $[17,22]$

\section{Implications of the new standards: provisional exploration}

The consequences of adopting these new standards are gradually becoming clear. It is expected that many hundreds of kilometres of primary flood defences must be reinforced and/or raised, because of raising the standards, because of expectedly higher flood levels due to climate change, or because of new insights in the strength and geotechnical behaviour of the flood defences. With the stricter performance demands, failure modes such as piping and macro-stability become relatively more important and require more sophisticated calculations.

A first provisional estimate of the required investment for meeting the standards in 2050 amounted 8.8- 14.2 billion euros [22], the majority for embankments along the Rhine and Meuse Rivers. This estimate comprised the consequences of the new standards as such $(>60 \%)$ as well as those of adapting to a higher sea level, increased river discharges and subsidence $(<40 \%)$. The estimate was based on the assumption that the reinforcements would be according to standard designs, including raising the crest to account for higher flood levels, changing the slope to account for instability and adding a berm to account for piping. And to be executed in soil unless the footprint would cause a conflict with existing buildings nearby. In the latter case reinforcement by inserting the more costly sheet-piling is assumed. The costs of the expectedly required reinforcements were calculated by applying the KOSWAT-tool, developed for this purpose [23].

It is obvious that such a large investment in flood protection calls for prudency and thorough consideration. 
And this is where good intentions and practice may get in conflict.

\subsection{Translating the protection standards to interventions: improving the flood defences in practice}

The obligatory 5-yearly assessment of all flood defences in 2001, 2006 and 2011 revealed that many embankments did not meet the then standards. This resulted in a programme of planned reinforcements (HWBP) currently comprising $731 \mathrm{~km}$ of flood defences in total. Subject to prioritization, many of these reinforcement projects are now being planned, designed and engineered.

However, designing the reinforcements has become a very difficult task for the responsible water boards, because of the two major changes in the design context. First, it is now almost certain that the standards are going to be changed, as explained above. Obviously the water boards desire to have their new embankments meet the new standards, and not only immediately after their delivery but also in 2050. It is common to design embankments for a life-time of about 50 years. And secondly, the technical requirements and toolkit for assessment and design are currently being adapted in order to be able to support an assessment in accordance with the new character of the standards: no longer to protect against a certain design flood level (exceedance probability), but to protect according to a certain performance requirement in terms of probability of failure. Up to now the flood defence has been assessed by: is it able to withstand a certain hydraulic load without significant damage? This is relatively easy to assess. In the future the flood defence will be assessed by: is the probability of failure less than the standard? This requires a sound definition of failure and complex calculations [cf. 24]. This is much more difficult.

The new requirements and assessment toolkit (WBI: Legal Assessment Instrument) are still 'under construction' and promised to be available by 2017. But the water boards that have to design their reinforcements cannot wait for this to be ready; they have to make decisions now, with huge financial consequences, and under large uncertainty. Not only uncertainty about the actual consequences of climate change and other future changes, but also about the new design requirements and assessment toolkit. The many uncertainties about the actual future developments complicate the decision making about the implementation of individual reinforcement projects, many of which are already being planned because the old standards were not met.

Relevant uncertainties in this context concern a) the actual rate and impact of climate change on the discharge regime $[25,26], b)$ possible actions or lack of action with our upstream neighbours, c) whether or not the policy of making room for rivers will be continued, d) actual economic growth and its impact on vulnerability and affordability of investments, but also e) new insights in the likelihood of failure of embankments through illunderstood mechanisms such as piping and macroinstability and their implications on the legal 'dike assessment instrument' (WTI) and the 'design instrument' (OI) which still drift about.

\subsection{The conflict between adaptive management and existing rules and regulations}

Adaptive delta management calls for prudency in implementation speed: not too much or too early, nor too little or too late. Or in other words: a variant of the precautionary principle is advocated. Even though it does not apply to activities related to pursuing economic gains with yet unknown or uncertain environmental side-effects (the usual category, for which the precautionary principle has been defined in the first place).

In contrast, the engineering practice of designing and constructing flood defences uses to call for prudency regarding performance: better safe than sorry. Even if that is somewhat more expensive. And connected to that it is common practice to construct for a number of decades in order to prevent having to come back for large-scale maintenance or even renewed upgrading. Reason for this is that the initial costs are usually large in comparison to the marginal costs, but also that the water boards do not like to bother the same stakeholders again and again, and partly for good reasons. But it also partly depends on the way of financing, where in the Netherlands the updating used to be entirely funded by the national authorities (nowadays only partly), whereas the maintenance is entirely at the cost of the responsible water board. This is, obviously, an incentive to opt for embankments that last already during the design and construction phase, and thus save on future maintenance. In the US this can be observed to an even larger degree, as the levees are usually constructed by the US-Army Corps of Engineers, whereas the maintenance is the responsibility of the regional authorities. It leads to a preference of the regional authorities for huge 'maintenance-free' constructions as well as to a tendency to negligence afterwards. Currently, the National Committee on Levee Safety of the American Society of Civil Engineers (ASCE) roughly estimates the cost to repair or rehabilitate the US levees to the required state to be about $\$ 100$ billion dollars.

Now these two approaches of prudency in implementation speed and prudency regarding performance would not be in large conflict, were it not for 1) the environmental side-effects of reinforcing flood defences, and 2) the influence on the possibility to apply other kinds of measures, or to shift to other strategies. In the past, reinforcement projects incurred massive opposition, because of the damage done to natural and cultural landscape values, and social and ecological values at large. In response, integrated approaches to the design of flood defences have been promoted and implemented, and in the Room for the River project the enhancement of 'spatial quality' has been set by government as explicit secondary goal for each individual project (alongside delivering risk reduction). This is generally acknowledged to be one of the key factors which make Room for the River so well-received, both by the local stakeholders and at the national level [27]. 
The current HWBP (flood protection programme) implementation programme does, however, not prescribe that other goals should be met in an equally obligatory way; only a guidance for spatial integration is provided, but for voluntary application.

The influence on the possibility to also apply other measures or shift to another strategy results from the fact that if the embankments are reinforced to a level required for 2050, the rationality of, for example, making room for rivers or building elsewhere or otherwise (flood-proof) is jeopardized. The benefit-cost ratio for such measures is then very low, making their large-scale deployment very unlikely; or a shift to another strategy, for that matter. If, however, the embankments would be reinforced to a level which is required at present (instead of in the future), it might become rational to also take other measures, namely in order to achieve a more sustainable country in view of further global change. One should, of course, be careful to spend money twice or unwise, where one thorough and integrated solution might have solved the problem for many decades to go.

A final addition to this description of the dilemma is that investing in the reinforcement of flood defences in the order by which they have 'come on the list' means that the first reinforcements taken-up may require so much time and money by aiming high, that other locations are being delayed. It could imply that the risk level for the entire country is not addressed in the most effective and efficient way. This makes the priority setting in the HWBP a very difficult task indeed, which is recognized by the responsible authorities and taken up with great care. Especially the balancing of what is optimal from a national perspective against what is practical from a local and regional perspective is very difficult.

In summary: the key question for practice is should one aim at immediately meeting the new standard on each planning site or gradually grow towards it while:

1. also investing in cost-effective flood risk reduction elsewhere?, and

2. keeping options open for other measures and/or a shift towards other strategies, more appropriate for the long-term?

\section{A way out: adaptive pathways, robust decision making and least regret options?}

Firstly, it is important to recognize that reinforcement projects can consist of very different measures, each partly of entirely effective in achieving the pre-set goal of risk reduction by reducing the probability of a certain failure mechanism occurring. In table 1 a number of possible measures are shown, and so is a gross estimate of their relative effectiveness in reducing the probability of failure per failure mechanism, and the relative costs of the measure. It shows that some measures influence all failure mechanisms, whereas others only influence one or two. This means that some are fully effective in reducing the failure probability on their own, whereas others need to be combined, depending on the situation and the dominant failure mechanism.

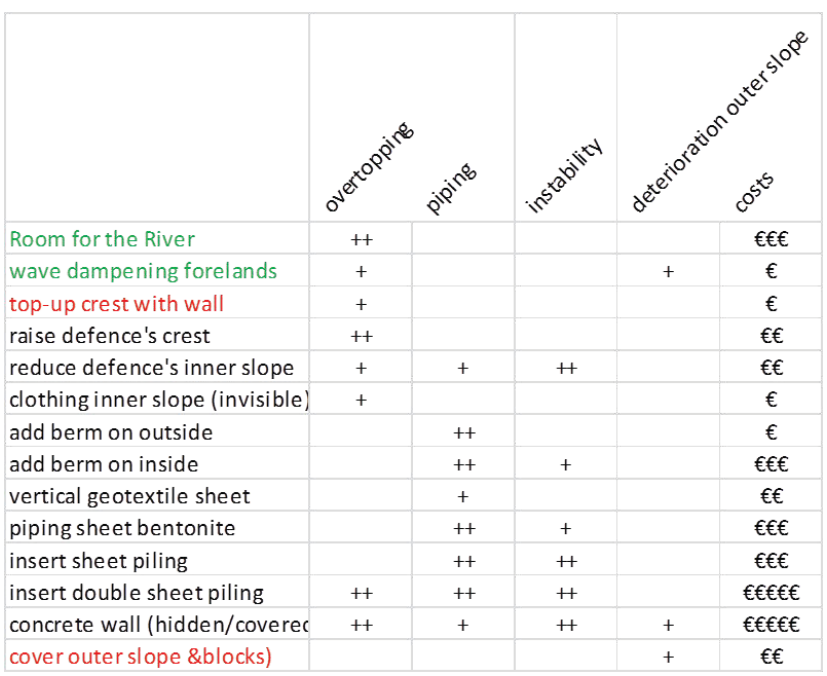

Table 1. Possible measures to reduce the load on the flood defences and/or to increase the defences' strength, with an estimate of effectiveness in reducing the probability of failure per mechanism and relative costs

From this set of measures, it is then possible to define which combinations of measures meet the desired goal, and in which order they may (or need to be) implemented. Especially when each measure can only influence one or two failure mechanisms, such an analysis of implementation pathways is relevant. For each step in a pathway, the effectiveness and costs can be estimated. The meticulously mapping out of implementation pathways is advocated as a very illustrative step to define all relevant options, and not only in terms of measures to include, but also in their expected life time and order of implementation (Figure 2).

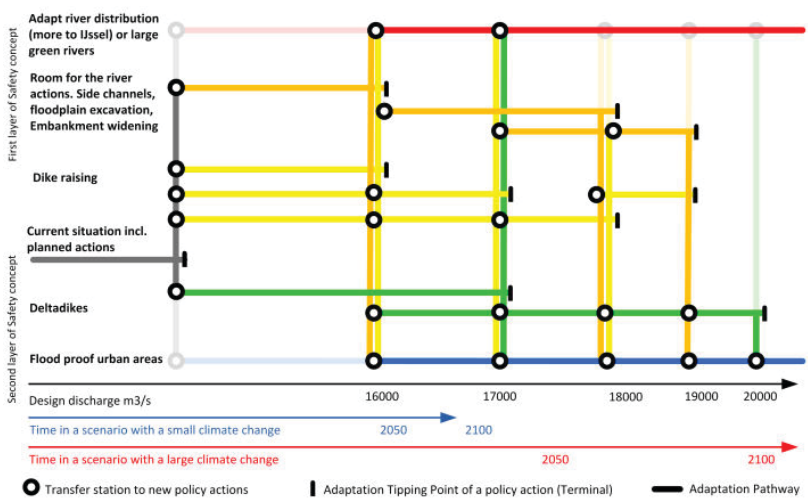

Figure 2. Example of identifying adaptive implementation pathways for measures which reduce the load to the embankments and/or their strength along the Rhine River [31].

For the Rhine and Meuse Rivers such a pathway mapping exercise is currently planned to be performed in order to define both the desired combination of room for river measures and reinforcement projects and their order of implementation along all river branches. 
Thirdly, the relevant options should be evaluated and compared. For individual reinforcement projects it is usual to base the precise dimensioning on requiremenst gegarding cost-effectiveness. Whether or not an option is cost effective, however, relies strongly on the discount rate. This means the outcome is very sensitive to the discount rate applied, whereas this is again very sensitive to the economic context taken into account when deciding on it. In the Netherlands, the discount rate was $5.5 \%$ during the Cost-Benefit analysis underlying the standard setting [20], but a working group recently advised to change it to $4.5 \%$ for cost-benefit analyses for infrastructure projects in support of economic development (a category which may be considered to not necessarily comprise flood defences!) and to $1 \%$ for cost effectiveness analyses when the benefits are not quantified [28]. The latter may be the case in reinforcement projects with the goal to achieve the "predefined standard' by 2050. The working group [28] specifically mentions three reasons for not applying a standard discount rate, namely 1) an uncommon risk profile due to future uncertainties (in our case caused by long-term climate and socio-economic change), 2) a deviating value development of non-market goods (in our case natural and cultural landscape values, which are negatively affected), and 3) project risks related to significant irreversibilities (in our case unnecessarily large infrastructure and large expenditures which preclude investing the money more cost-effectively on flood risk reduction elsewhere).

For such cases, the working group [28] calls for at least taking into account different scenarios in order to account for the future uncertainties, and preferably to apply more sophisticated approaches in any infrastructure project which comes with high investment costs. In such a case a real options approach is more appropriate, at least when one desires to stick to a predominantly economic approach. In a real options approach, not only the effects of the measure as such should be valued, but also the option of delaying investments [29, 30]. This translates into a higher cost-effectiveness requirement.

Because of the many difficulties in applying the real options approach in practice, it is, however, not uncommon to evaluate alternative implementation pathways [cf. 31] with different orders and timings per measure in terms of advantages and disadvantages and by a much more diverse set of criteria. This allows evaluating the (partial) delay of implementation and the (dis)advantages of flexibility. It also implies that the difficulty of expressing (almost) all relevant costs and benefits in monetary terms can be avoided, and also the problems with discounting. An interesting criterion to evaluate adaptive implementation pathways by, is decision robustness [32]. This questions not which alternative option performs best in one scenario, but which alternative performs satisfactory in all future scenarios.

By focussing on performance, decision robustness puts emphasis of desired or intended effects (in our case risk reduction) against costs in a very similar way as economic optimization does. To account for a much broader spectrum of values, we prefer to assess alternative options against more criteria and to explore which alternative implementation pathway comes with the least regrets. Regrets in terms of money spent too early or unwisely, but also regrets because of irreversible impacts on natural or cultural landscape values, because of induced changes causing the whole system to become more vulnerable and susceptible to future uncertainties. And in so doing, to scale up the assessment to not just one individual project but to the country-wide implementation of risk reducing measures; after all, it is national money being spent for a common good. Such an approach could help us identify which implementation pathway yields the most robust flood risk system [33] and comes with the largest added values for the entire manenvironment system. Identifying this alternative and translating it into practical guidelines for implementation is a challenge to address in the next years.

\section{References}

1. Botzen W.J.W., Van den Bergh J.C.J.M. and Bouwer L.M. (2010) Climate change and increased risk for the insurance sector: a global perspective and an assessment for the Netherlands. Natural Hazards $\mathbf{5 2}$ : 577-598

2. Bouwer L.M., Bubeck P. and Aerts J.C.J.H. (2010) Changes in future flood risk due to climate and development in a Dutch polder area. Global Environmental Change 20: 463-471

3. Klijn F., Baan P., De Bruijn K.M., Kwadijk J. (2007) Flood risks in the Netherlands in a changing climate; expectations, estimates and calculations for the 2nd Sustainability Outlook for the Netherlands. Delft Hydraulics report Q4290, Delft (in Dutch)

4. Klijn F., Kwadijk J., De Bruijn K.M. and Hunink J. (2010) Flood risks and drought risks in a changing climate; survey of pathways to climate-change proofing the Netherlands. Deltares report 1002565, Delft (in Dutch)

5. Klijn F., De Bruijn K.M., Knoop J. and Kwadijk J.C.J. (2012) Assessment of the Netherlands' flood risk management policy under global change. Ambio 41:180-192

6. Ten Brinke, W.B.M and Bannink B.A. (2004). Dutch dikes and risk hikes. A thematic policy evaluation of risks of flooding in the Netherlands. RIVM Report 500799002, Bilthoven (in Dutch)

7. Delta Committee (2008) Working together with water. A vital country builds its future. The Hague (in Dutch)

8. Delta Programme, 2011. Delta Programme 2012: Taking measures now, preparing for tomorrow (in Dutch). Ministry of Infrastructure and Environment and Ministry of Economic Affairs, Agriculture and Innovation, The Hague.

9. Holling C. (1978) Adaptive environmental assessment and management. Wiley, Chichester, UK.

10. McLain R. and Lee R. (1996) Adaptive management: promises and pitfalls. Environmental Management 20/4: 437- 448 
11. Pahl-Wöstl C., Sendzimir J., Jeffrey P., Aerts J., Berkamp G. and Cross K. (2007) Managing change towards adaptive water management through social learning. Ecology and Society 12/2: 30 (online)

12. Medema W., McIntosh B. and Jeffrey P. (2008) From premise to practice: a critical assessment of Water Resources Management and Adaptive Management approaches in the water sector. Ecology and Society 13/2: 29 (online)

13. Walker W.E. (2000) Policy analysis: a systematic approach to supporting policymaking in the public sector. Journal of Multi-Criteria Decision Analysis 9(1-3):11-27

14. Thissen, W.A.H and Walker W.E. (eds) (2013) Public Policy Analysis, New Developments. International Series in Operations Research \& Management Science, Volume 179, Springer.

15. Kwakkel J.H. and Pruyt E. (2013) Exploratory Modeling and Analysis, an approach for modelbased foresight under deep uncertainty. Technological Forecasting and Social Change 80/3: 419-431

16. Van Rhee G. (2012) Handreiking Adaptief Deltamanagement (in Dutch). Stratelligence, Leiden

17. Van der Most H., Tánczos I., De Bruijn K.M., Wagenaar D. (2014) Development of new, risk-based standards for flood protection in The Netherlands. Proceedings of the ICFM6 conference, September 2014, Sao Paolo, Brasil

18. Klijn, F., Samuels P. and Van Os A. (2008). Towards Flood Risk Management in the EU: state of affairs with examples from various European countries. Journal for River Basin Management 6(2008)/4: 307-321

19. Bubeck, P., Kreibich H., Penning-Rowsell E.C., Botzen W., De Moel H. and Klijn F. (2015). Explaining differences in flood management approaches in Europe and the USA - A comparative analysis. DOI: 10.1111/jfr3.12151, Journal of Flood Risk Management.

20. Kind J.M. (2014). Economically efficient flood protection standards for the Netherlands. Journal of Flood Risk Management.

21. De Bruijn K.M., Klijn F., Van de Pas B. and Slager C.T.J. (2015). Flood fatality hazard and flood damage hazard: combining multiple hazard characteristics into meaningful maps for spatial planning. Nat. Hazards Earth Syst. Sci., 15, 12971309

22. Anonymous (2014). Technisch-inhoudelijke uitwerking DPV 2.2: consequentieanalyse voor primaire keringen (september 2014). (in Dutch).

23. Deltares (2014). KOSten voor versterking WATerkeringen. KOSWAT, systeemdocumentatie. Deltares, Delft. (in Dutch).

24. Slomp R., Knoeff H. and Bottema M. (2016). Probabilistic Flood Defence Assessment Tools. Proceedings of the FLOODrisk2016 conference Lyon/this volume.

25. Sperna Weiland F., Hegnauer M., Bouaziz L. and Beersma J. (2015). Implications of the KNMI'14 climate scenarios for the discharge of the Rhine and
Meuse; comparison with earlier scenario studies. Deltares report 1220042-000, Delft

26. Klijn, F., Hegnauer M., Beersma J. and Sperna Weiland F. (2015). Wat betekenen de nieuwe klimaatscenario's voor de rivierafvoeren van Rijn en Maas? Samenvatting van onderzoek met GRADE naar implicaties van nieuwe klimaatprojecties voor rivierafvoeren. (in Dutch) Deltares \& KNMI, Delft.

27. Klijn, F., De Bruin D., De Hoog M., Jansen S. and Sijmons D. (2013). Design quality of Room-for-theRiver measures in the Netherlands: role and assessment of the Quality Team (Q-team). Journal of River Basin Management 11(2013)/3: 287-299

28. Anonymous (2015). Report Working Group Discount Rate 2015.

29. Haigh N. and Fisher J. (2010). Using a "Real Options" approach to determine a future strategic plan for flood risk management in the Thames Estuary. Draft Government Economic Service Working Paper.

30. Woodward M, Kapelan Z, Gouldby B (2014) Adaptive flood risk management under climate change uncertainty using real options and optimisation. Risk Analysis 34/1:75-92

31. Haasnoot M (2013) Anticipating Change. Sustainable Water Policy Pathways for an Uncertain Future. PhD thesis, UT Twente. ISBN 978-90-3653559-5

32. Lempert R.J. and Collins M.T. (2007). Managing the Risk of Uncertain Threshold Responses: Comparison of Robust, Optimum, and Precautionary Approaches. Risk Analysis 27(2007): 1009-1026

33. Klijn, F., Mens M.J.P. and Asselman N.E.M. (2015). Flood risk management for an uncertain future: economic efficiency and system robustness perspectives compared for the Meuse River (Netherlands). Mitigation and Adaptation Strategies to Global Change (MITI), 20(2015)/6:1011-1026 